\title{
Dental Students' Reflections on Clinical Placement in a Rural and Indigenous Community in Australia
}

\author{
Ratilal Lalloo, B.Ch.D., B.Sc.Med. Hons (Epidemiol), M.Ch.D., Ph.D.; \\ Jane L. Evans, B.F.E.T., Ph.D.; Newell W. Johnson, M.D.Sc., Ph.D., FDSRCS (Eng), \\ FRACDS, FRCPAth (UK), FFOP (RCPA), FHEA (UK), FICD
}

Abstract: Clinical placements away from the dental school are now an integral and important component of dental education internationally. This article presents feedback from students on their experience in a remote rural clinical placement in Australia by year cohorts 2009, 2010, and 2011. An online feedback survey instrument and compulsory reflective journals were analyzed both by calendar year cohort and amongst individual student groups. The information obtained suggests that overall this was a very positive experience for most students and the clinical experience gained was valued highly. Many students wrote positively about their cultural experiences and the knowledge they gained of life in a remote rural area. Many were pleased with the contribution they made to the oral health treatment needs of the community. Concerns related to the lower patient flow and the inferior quality of equipment compared to that in the main university clinic and with delays in maintaining and repairing equipment. While the overall outcome was positive, significant challenges face all stakeholders to maintain and enhance the clinical and social experiences of these future practitioners. The true impact of the placement will only be realized when graduates are confident to venture into clinical practice settings in rural locations.

Dr. Lalloo is Colgate Chair and Professor of Rural, Remote, and Indigenous Oral Health, School of Dentistry and Oral Health and a member of the Population and Social Health Research Program, Griffith Health Institute, Griffith University, Australia; Dr. Evans is Senior Lecturer in Dental Technology, School of Dentistry and Oral Health and a member of the Population and Social Health Research Program, Griffith Health Institute, Griffith University, Australia; and Dr. Johnson is Professor of Dental Research, Griffith Health Institute, the Lead for Population Oral Health, Population and Social Health Research Program, Griffith University, and the Foundation Dean, School of Dentistry and Oral Health, Griffith University, 2005-09. Direct correspondence and requests for reprints to Dr. Ratilal Lalloo, DOH, Gold Coast Campus, Griffith University, QLD 4222, Australia; r.lalloo@griffith.edu.au.

Keywords: dental education, clinical education, community-based dental education, remote rural placement, dental students, reflection, Indigenous communities, Australia

Submitted for publication 7/31/12; accepted 10/3/12

$\mathrm{T}$ The benefits of outreach training in a dental program have been succinctly summarized by a special interest group on outreach training of the Association for Dental Education in Europe (ADEE). ${ }^{1}$ The benefits extend well beyond the expected enhancement of competencies related to the clinical work performed; just as importantly, they lie in the exposure of students to a setting vastly different from that provided by the main dental school and university clinic. ${ }^{2-4}$ In the literature on this subject from around the world, student feedback on clinical placements is generally positive. ${ }^{5-15}$ Students talk positively of the broader clinical experiences and of having to adapt approaches and practices to different settings; of the importance of a team approach to patient care; and of gaining a broader view of health care. They also appreciate the ready accessibility of teaching staff and recognize the closeness of the learning experience to subsequent practice. Students who attend a rural rotation show an appreciation of the opportunity to gain insight into an unfamiliar setting, noting that oral health in rural communities is significantly worse than among the metropolitan patients for whom they have previously cared..$^{5-8}$ They gain an understanding of the difficulties in recruiting dental professionals to these types of settings. Students also see the challenges arising from the lack of technical and specialist support and the difficulties of servicing and repairing equipment.

In Australia, oral health practitioners, especially dentists and dental specialists, work predominantly in the private sector, in state capitals, and in other large cities and towns. ${ }^{16-19}$ Dental schools, and therefore dental education and training, are usually located in cities, and the clinical exposure of students is predominantly urban-based. In 2009, the School of Dentistry and Oral Health at Griffith University, based in the City of Gold Coast, southeast 
Queensland, Australia, and in partnership with the local shire council, embarked on a clinical placement in the remote rural town of Brewarrina in New South Wales (NSW), Australia. The fundamental aim of the placement is to reveal to students during their undergraduate training that there are options to develop a satisfying professional career in a rural and remote setting. It is hoped that the placement will make the students appreciate the general and oral health burdens experienced by rural, remote, and Indigenous communities in Australia, as well as the risk factors these residents confront on a daily basis. There is consensus that the burden of dental conditions is higher in rural and remote locations, especially amongst Indigenous people in these areas. A recent report on the dental caries status of Indigenous children in Australia showed that those located in rural and/or remote areas have much higher mean number of decayed, missing, and filled deciduous teeth (DMFT) ( $\sim 4$ in six-year-old children) compared to non-Indigenous children in metropolitan (DMFT $\sim 1.5$ ) and rural settings (DMFT $\sim 1.8$ ) as well as Indigenous metropolitan children (DMFT 2.6). ${ }^{20}$ The situation is the same in the permanent dentition of older children. The National Survey of Adult Oral Health found that 57 percent of Indigenous adults had untreated coronal dental caries, compared with 25 percent of non-Indigenous adults. ${ }^{21}$ The mean number of decayed teeth amongst Indigenous adults ( $>15$ years of age) was 2.7 compared to 0.8 amongst non-Indigenous adults. Indigenous adults were however underrepresented in this survey, and the findings need to be interpreted with caution.

Students in the fifth (final) year of their preregistration program at our school spend three weeks at this remote rural clinical placement. They learn cultural awareness and provide health promotion, prevention, and basic dental services to the people in the town and surrounding areas. The students experience a setting that is previously outside the experience of most of them. This town is about 900 kilometers from the dental school and the cities on the east coast of Australia and is nearly 200 kilometers from the nearest large town/regional center; travel to Brewarrina requires a twelve-hour bus journey. Brewarrina itself has a population of about 1,500, with a further 500 people in its hinterland over a radius of 20,000 square kilometers (sq km). The town has a public primary school with 200 pupils. Seventy percent of the population identify themselves as of Indigenous (Australian Aboriginal) origin. The land area of Australia is 7.5 million sq km (the sixth largest country in the world), with a total population of 22.3 million. While most people live in the metropolitan cities, almost a quarter of Indigenous people live in remote or very remote parts of the country.

Students on this rotation live together in a large house provided by the local shire council, which is partially serviced in terms of cleaning and cooking. Other than that, students prepare their own meals from food provided and are responsible for personal laundry. The town has good recreational facilities, especially for sports. The locals are very welcoming and often offer considerable hospitality, including opportunities to participate in country pursuits such as fishing, hunting, attendance at horse races, and sheep shearing. The clinic has four dental surgeries in newly renovated accommodations. Initially, these were equipped with mobile chairs and dental units, but were upgraded to fixed equipment in the second year of operation. Staffing includes a supervising dentist, a dental assistant, and a receptionist. In the three years (2009 to 2011) of the project so far, 166 of the total 174 ( 95 percent) final-year dental students have completed this placement in Brewarrina. Students are usually rotated in groups of eight.

To improve the quality of the clinical placement, student feedback is continually sought. Much current research on student feedback is based on urban and regional clinical placements, and little is reported on remote rural placements. The aim of this study was to compare students' feedback on their rural clinical placements by year cohorts and by individual student groups, by analyzing common themes and concepts in their reflective journals and their responses to an online feedback survey.

\section{Methods}

Several approaches were used to analyze differences between year cohorts and between groups within years. Student experiences are monitored through an anonymous voluntary online survey and submission of a compulsory reflective journal - the latter being the formal assessment of the clinical placement module in the curriculum for the final year of prequalification studies. Questions asked in the survey are listed in Table 1; response options range from strongly agree to strongly disagree. This survey was conducted in 2010 and 2011.

Student journals are common reflection activities in community service-learning courses. ${ }^{22}$ In these, students were asked to highlight the strengths 
Table 1. Responses to closed-ended statements on surveys for 2010 and 2011, as percentage of total respondents

\begin{tabular}{|c|c|c|c|c|c|}
\hline Statement & SA & A & $\mathrm{N}$ & $\mathrm{D}$ & SD \\
\hline I understood the aims of the option before my placement occurred. & $24 \%$ & $60 \%$ & $13 \%$ & 0 & $3 \%$ \\
\hline $\begin{array}{l}\text { The clinical consultants provided a satisfactory level of support and guidance } \\
\text { throughout my placement. }\end{array}$ & $44 \%$ & $39 \%$ & $9 \%$ & $5 \%$ & $3 \%$ \\
\hline $\begin{array}{l}\text { I increased my awareness of the contribution made by the environment (physical, } \\
\text { economic, and social) and dental services to the dental welfare of the public. }\end{array}$ & $41 \%$ & $48 \%$ & $6 \%$ & $4 \%$ & $2 \%$ \\
\hline $\begin{array}{l}\text { I gained an appreciation of the day-to-day organization of the clinical environment } \\
\text { including health and safety. }\end{array}$ & $31 \%$ & $50 \%$ & $14 \%$ & $3 \%$ & $3 \%$ \\
\hline I increased my appreciation of the importance of teamwork within the dental team. & $37 \%$ & $44 \%$ & $14 \%$ & $6 \%$ & 0 \\
\hline I developed skills of patient management including communication skills. & $32 \%$ & $49 \%$ & $15 \%$ & $4 \%$ & 0 \\
\hline I developed clinical operative skills in a primary care environment. & $32 \%$ & $52 \%$ & $11 \%$ & $5 \%$ & $1 \%$ \\
\hline I learnt to effectively utilize the resources available to deal with problems confronted. & $42 \%$ & $44 \%$ & $10 \%$ & $2 \%$ & $3 \%$ \\
\hline I learnt to work independently. & $38 \%$ & $45 \%$ & $14 \%$ & $2 \%$ & $2 \%$ \\
\hline I believe this option has provided me with a valuable learning experience. & $37 \%$ & $46 \%$ & $11 \%$ & $5 \%$ & $2 \%$ \\
\hline I am now more likely to choose a career in the public sector. & $8 \%$ & $25 \%$ & $40 \%$ & $18 \%$ & $10 \%$ \\
\hline I would recommend this option to future students. & $37 \%$ & $35 \%$ & $17 \%$ & $8 \%$ & $3 \%$ \\
\hline I am now more likely to work in a rural and remote setting. & $15 \%$ & $25 \%$ & $29 \%$ & $18 \%$ & $14 \%$ \\
\hline The transport and accommodation for my placement were arranged to my satisfaction. & $34 \%$ & $26 \%$ & $23 \%$ & $9 \%$ & $8 \%$ \\
\hline
\end{tabular}

and limitations of the clinical placement and suggest recommendations for improvement. The reflection journals were implemented from the start of the placement program in 2009.

For the survey, the frequency distribution of responses to the close-ended statements and the general comments were analyzed. The reflective journals were analyzed using the specialized software package Leximancer. ${ }^{23,24}$ This is a text analysis application that clusters words and phrases to identify common or repeated themes and concepts. A thesaurus of words related to particular concepts is automatically developed and displayed visually to show their co-occurrence and interconnectedness: this is known as a concept co-occurrence matrix. The method removes researcher bias in interpreting large amounts of written material. The Griffith University Human Research Ethics Committee approved the research proposal (GU Ref No: DOH/22/10/HREC).

\section{Results}

Over the two years in which the survey was conducted, a total of 82 percent of the students provided feedback via the online survey: most were overwhelmingly positive about their experiences. In 2010, forty-eight of the fifty-three students (91 percent) responded; in 2011, fifty-two of the seventy students (72 percent) responded. There were no major changes to the program structure, living conditions, clinical setting, community engagement, or supervisory arrangements over this time. Unsurprisingly, therefore, there were no significant differences between the responses provided by the students by year cohorts, and the data have been combined for analysis.

Over 80 percent of the participating students responded positively to most of the individual statements (Table 1). These included recognition of the positive contribution made simply by the university's presence, the impact of clinical services provided to the dental welfare of the public, the challenges of day-to-day organization of the clinical environment, the importance of teamwork, and the process of learning to work independently. Less than a third of these students felt they were now more likely to choose a career in the public sector, although 40 percent said they were more likely to work for some of their career in a rural and remote setting.

The free text comments highlight both positive and negative aspects of the experience and reveal the difficulties of this type of project for all stakeholders. Examples of general comments include the following:

- "Bre was a great experience and 3 wks was a perfect amount of time. Clinically I learnt how to use what I had and appreciate all that I have at GH1/ metro areas in general" [GH1 is the university dental clinic]. 
- "Very good experience at working on cases where referral was not an option."

- "Thank you for organizing an excellent outplacement. It was a great learning experience. Hope to have more patient flow in the future."

- "Work was great; however, weekends were quite boring. We didn't do anything on the weekends at all."

- "A fantastic experience. Was excellent in learning how to deal with fearful patients. But not very beneficial to learn clinical skills due to poor patient flow. But I feel it was still very valuable as it is important for students to have exposure to rural communities so they can appreciate/understand the challenges faced by people living in them."

- "Bre was a fantastic placement. . . gave us the greatest placement experience I could have hoped for. I enjoyed the placement and think it has definitely put perspective to my role as a dentist and to my future employment plans."

The reflective journals were completed by the 2009 cohort (six groups), the 2010 cohort (seven groups), and the 2011 cohort (eight groups). From the 2009 reflective journals, Leximancer analyzed 2,239 total segments, from which forty-three major concepts emerged. The 2010 cohort wrote less than the previous year: Leximancer analyzed 647 total segments and found thirty-four concepts. From the 2011 cohort, Leximancer analyzed 1,143 total segments and found thirty-five concepts. We provide here an overview of student experiences and then discuss the strengths, limitations, and future direction of the Brewarrina placement as commented on by students in their reflective journals. All groups most often talked about the patients and the clinic and mentioned broader concepts of the community and health less often.

Members of the very first group (group 1, 2009 cohort) to experience the Brewarrina placement said they were unsure of what lay ahead, given the absence of preceding peers to consult. They noted being grateful for the powerful welcome with which the local community received them. In contrast, the 2011 cohort reflected more on their living arrangements and less on social interactions with the local community: most reflections related to the clinical or health perspectives from an outsider's viewpoint, rather than their lived experiences within the broader community.

The Brewarrina placement appeared to be a very positive learning experience for the students.
All cohorts acknowledged that communicating health promotion messages to the whole local community and providing oral hygiene instruction to individual clients were key parts of their role. The 2009 and 2011 cohorts spoke more of providing "care" rather than "treatment." The 2009 cohort tended to label the experience as "unique" and "valuable." Students in the 2010 cohort acknowledged the extensive comprehensive care they were able to deliver in a team environment seeking a common goal, said by one "to improve the quality of health for each patient." A 2010 student was relieved to know the participants could "handle the workload" after seeing "numerous patients, ALL DAY." Others across the three cohorts expressed that the outplacement enhanced their learning and increased skills because they were exposed to a variety of complex cases, particularly in oral surgery. The low student to tutor ratio was valued. The later cohorts valued the diversity of oral conditions and the wider case mix than that to which they were accustomed in the university clinic. One member of the 2010 cohort mentioned being struck by the rural patients' tolerance for poor dental health: "they put up with periapical lesions, severe periodontitis, tooth fracture, retained roots, and generalized decay ... for months not days."

Students in the 2009 cohort commented on the multiple roles played by everyone in the clinic and the resourcefulness of staff and students who constantly sought viable alternatives when placed in difficult circumstances. Similarly, one student in the 2010 cohort wrote that "working together with the other health workers in the community made me realize the value of teamwork and having sound communication between all members."

The 2009 and 2010 groups recognized in their comments that learning was not isolated to the dental clinic, but provided "life-learning," as one put it, that was significantly increased through interactions with the local community. A member of the 2010 cohort commented that the students acquired skills to "communicate in a light-hearted friendly manner" in order to "gain trust and cooperation." Not only were their clinical skills improved, this student added, but their social and life skills were enhanced: "spending time with locals was an integral part of our learning experience." After the experience students said they believed they could work effectively in a rural environment in the future. The contribution of the local community in their enjoyment of the experience was acknowledged by one member of the 2010 
cohort, who wrote, "if it were not for the Brewarrina experience, I think I would never consider working somewhere rurally, but now I can."

Members of the 2011 cohort commented that the clinic was now well known in the area. One student commented that "access and health promotion remain limited; however, the clinic is well known through the region, and through school visits and the presence of students in the surrounding communities there is an element of preventive treatment prevailing with several patients."

Members of group 4 in 2009 reported seeing a significant difference in oral health status between patients at the university and at the rural clinic. They thought this was due to the lack of access to dental health services over a long timeframe and said they hoped this placement program could contribute to an improvement over time. Some groups within the 2011 cohorts focused on learning skills rather than provision of care; however, the majority of groups considered the patient as central. The following quote from a student in the 2009 cohort exemplifies the strengths of the Brewarrina placement: "The success of our placement was mainly attributed to our keen approach to the Brewarrina experience, both inside and outside of the clinic. We had open minds and were not afraid to venture into the unfamiliar. We made an effort to get to know the locals and be involved in community activities such as trivia nights and attend an art exhibition."

The students, however, also identified a number of limitations at the rural placement. At the beginning there were, perhaps inevitably, issues with installation and functionality of equipment and organizational matters such as difficulties with the patient booking system. Members of the 2009 cohort said they believed these challenges could be overcome. These issues were indeed progressively resolved, and as students performed more treatments, the experience became more and more positive over time. A student in the 2009 cohort commented, "We recognized the differences of living in a rural community and individualized certain options based on the level of technology available to not only us as clinicians but the patients themselves."

Although equipment and management issues were resolved over time, students in the 2010 and 2011 cohorts still spoke of the gap between the number and quality of resources on placement compared to those at the university. Some called the equipment substandard. Some groups from the later cohorts also expressed disappointment that the number of patients treated during their placement failed to meet their expectations, and one student in the 2010 cohort noted finding "patient flow to be a frustration."

Some students in each cohort reported seeing logistics and timing of the placement as problematic. Members of the 2009 group expressed valid concerns that their electronic access to the university's online learning sites (e.g., to access lectures they could not attend in person) was suboptimal as Internet access at the accommodation was limited. This concern was not expressed to the same extent in the following years since Internet access was significantly improved.

The students did not often provide recommendations to improve the clinical placement. Members of group 2 in the 2010 cohort recommended increased integration of care in which dental technology students might be included in the outplacements to "provide simple removable prosthesis to patients," as one wrote. Students in groups 3 and 8 from the 2011 cohort acknowledged the service provision to the local community but contemplated the extension of service provision to the greater communities who have limited access to services.

\section{Discussion}

The strength of this remote, rural, and Indigenous placement most commonly expressed across all three cohorts of students and by most groups was the value to them of the clinical, patient care experience. The range of clinical cases they treated, especially in the absence of the ability to refer or seek specialist advice, and the lower student to tutor ratio were seen as major benefits. Evaluations of clinical placements elsewhere have found that positive clinical experiences are often mentioned by students in their feedback. ${ }^{4,6,7,9,11}$ It is not surprising that students often reflect on their clinical experiences (positively and negatively) when on placement. In their overall training, the clinical and technical aspects of the program take precedence. Most courses, mainly due to time pressures, essentially focus on ensuring that students are clinically and technically competent and confident in performing the numerous clinical procedures students need to master. While the student guide for the rural clinical placement emphasizes the "bigger picture" of health and well-being and the importance of community on this placement, 
the students' journals most often reflected on the clinical experiences in terms of patients, patient care, patient flow, clinic equipment, and management. Students may not have reflected on the nonclinical/ training-related activities as they may not consider these appropriate for a formally assessed assignment.

The instructions for the reflective journal have changed over time, making it clearer that the reflections should be about the overall experience, not only the clinical aspects of the placement. The pre-briefing information meetings with each student group now more explicitly emphasize that the placement is more than a purely clinical one-emphasizing, for example, the importance of community engagement and being aware of social histories unique to living in a remote rural setting. Significant efforts are already in place to improve the nonclinical experience of the students on this placement. For example, the university and shire council arrange at least one visit to a neighboring town, and an extensive list of social activities is readily available. Students are encouraged to attend social events in the town and thereby connect with the local community. This has often led to students being invited to the homes and farms of community members for a variety of activities. Students have to make efforts themselves to become aware of the bigger picture rather than to focus merely on the immediate clinical situation. Although stated less frequently (compared to clinical experience), students have praised the positive response of the community towards them and the clinic and have said they appreciate the opportunity to experience a setting very different from their urban-based university.

A further important strength of this rural placement was that the students had an opportunity to experience the friendly welcome and engagement of the local community. Being in a small setting allows students to connect with the community and develop skills of engagement that could be more difficult in a large urban-based dental clinic. Developing cultural competencies in dental students is an important component of dental programs.

All cohorts reflected on the significant difference in oral health status between patients at the university and at the remote rural clinic. Mostly, they thought this was due to the lack of access to dental health services over a long timeframe - an interesting observation as it is suggested that dental services in themselves contribute only a minor part to any overall improvement in oral health status of a population. ${ }^{25}$ The supervising staff to student ratio at this placement is $1: 4$, compared to the university dental clinic ratio of 1:6. The lower ratio and easily accessible supervisor in this small clinic setting were highlighted as significant positive aspects of the placement.

The negative aspects of the clinic noted by students mainly related to the lack of patient flow. Whilst this is true to some extent, and perhaps expected in a remote rural town, the percentage of appointments not attended (failed to attend) was about 19 percent in 2011. In a rural and disadvantaged community, this level of nonattendance is expected as people often have to deal with urgent matters at short notice and many have to travel long distances. Students need to be aware of the issues related to patient flow in remote rural settings. The marketing and profiling of the dental clinic are, however, continually being addressed by all stakeholders in the program. This includes regular advertisements of the clinic in the local newspaper, often including a full page of interviews (mostly light-hearted) with students at the clinic. All schools in the town and surrounding towns are offered health promotion and screening activities, and reports are sent home with children to parents, recommending a visit to the clinic if required. All local health care providers, especially referring general medical practitioners, are informed of the details of the placement and are encouraged to refer patients when dental care is needed. Both the dental school and the shire council have given many interviews to the regional radio station. The dental clinic has also received national recognition: a prize in the 2010 National Awards of Local Government (www. minister.infrastructure.gov.au/aa/releases/2010/June/ AA403 2010.aspx). The dental clinic was awarded both the National Award for Excellence and won the top honor in the Rural and Remote Health category. These awards provided all stakeholders with excellent marketing material.

The quality of the equipment was initially a common concern among students. At the outset of the clinic in 2009, it was decided to install portable dental equipment, so that it could be used on school visits or utilized in other communities in the future. The equipment was, however, prone to breakdown, principally due to fluctuations in power supply, and often not all four surgeries were fully functional. In terms of ergonomics, the equipment was not appropriate for operator and assistant use for eight hours a day, five days a week, especially with students who 
have not previously worked full-time in a clinic. In 2010 and 2011, fixed equipment was sourced from the public service by the shire council, and students' complaints about equipment breakdown decreased considerably as a result. However, odd occasions persisted when the clinic had to be closed due to significant maintenance issues, for example, related to power supply and plumbing problems. In such a remote setting, it can take days to obtain repair services because workers may have to travel from a base far away. Issues such as these do help to make students aware of the realities of distance and isolation and its impact on service delivery.

The long distance between the university base and the remote rural placements is also a significant logistical complication. Students travel twelve hours on the bus to get to the town, confronted by the inherent dangers of long-distance travel. Fortunately, no major incident has occurred. Also being far from base means that dealing with personal emergencies is difficult, as getting back to base can take most often more than a day. Again, personal emergencies have been very few. Communication is not an issue: both landline telephone and Internet access are available at the clinic and the accommodation, so students can be easily contacted by family and friends.

Whilst the issue of staffing the clinic was not often raised in the students' reflective journals, this was a significant management concern for the sustainability of the placement. Prior to 2011, the placement convenor had to source a supervising dentist and occasionally a dental assistant from existing school academic (full-time or casual) and clinic staff for each rotation. There were times when staffing for a rotation was confirmed only at a late stage. To avoid having to find staff for each rotation and the inherent problems of continually changing staff, it was decided to recruit a longer term supervising dentist and dental assistant from a health recruiting employment agency in the region. In 2011, all but the first rotation was supervised by the same dentist, and two dental assistants covered all the rotations. The staffing costs are higher under this arrangement, but the added costs outweigh the negative impacts of changing staff for each of the rotations and the staff have brought about stability in the local management and operations of the clinic. No formal feedback has been gathered from the supervising dentists, but informal verbal and voluntary written feedback suggests that the dentists have been impressed with the quality of the clinical experience offered to the students. They have expressed concerns relating to the percentage of broken appointments and the quality of the mobile equipment initially installed. A quote from a supervising dentist in 2009 summarized the positive response of the clinical supervisors: "I believe the program is successful on many fronts. First, it is a unique experience for the students both professionally and socially. I believe it is a wonderful opportunity to achieve adaptability in treatment planning and procedures in a stimulating environment. Secondly, the clinic provides a much appreciated service to the local community and the surrounding communities which lack access to dental care. The clinic also serves as a very successful joint activity with the shire whose support is both substantial and practical."

While a significant percentage of the students expressed a greater likelihood of working in the public service ( 33 percent) and in a rural remote setting (40 percent) after the placement, the forces driving new graduates to take up employment in the private sector in metropolitan areas are considerable. ${ }^{26,27}$ This is unlikely to change significantly as dentistry is a market-driven profession. Our 2009 dental graduates, the first who experienced the rural placement, were asked about their employment status a few months after graduation. About 60 percent of them responded to the survey; of those, 80 percent were in the private sector, and more than two-thirds in the capital cities. The main reasons expressed for not opting for employment in a small town were to be close to family and home and the professional support and social life in a city/large town. Currently, most dental students graduate with considerable debt. Income in the private sector outstrips that in the public sector by a large amount, even for new graduates. The beneficial impact of this rural clinical experience might therefore only be realized when these graduates are professionally confident and financially secure enough to venture into clinical practice settings in rural locations.

\section{Conclusion}

The Brewarrina rural clinical placement appears to be beneficial for the overall clinical experience of the dental students at Griffith University. A second clinical placement in a regional setting (less remote and closer to the university base) is now available to our students. Issues related to appreciating the 
bigger picture, patient flow, fully functional dental surgeries, turnaround time on repairs, and consistencies in staffing are challenges confronting all partners in this project. Current research being conducted includes an overview of the patient numbers and types of care provided, a detailed analysis of the patient flow and clinic downtime due to maintenance issues, and a cost analysis of the remote rural clinical placement. Further research on the opinions of relevant stakeholders on the broad issues of oral health and its improvement in rural, remote, and Indigenous communities and service user opinions on the dental clinic is currently being conducted. Detailed discussions with stakeholders are important in that student placements can only be implemented in a few remote rural communities and therefore will have a relatively small impact on the level of untreated dental disease and ultimately on the prevention of these conditions across the nation. The issue of oral health in rural, remote, and especially Indigenous communities needs a holistic, common risk-factor approach, ${ }^{28}$ in which the social determinants of health must be addressed. ${ }^{29-31}$

\section{Acknowledgments}

This placement is primarily in partnership with the Brewarrina Shire Council, based on a Service Level Agreement. The Shire Council has a separate agreement with the NSW Greater Western Area Health Service to support the dental clinic. The clinical placement is funded by the Commonwealth Grant for Dental Training - Expanding Rural Placements Program (DTERP). Further funding to build capacity was also provided by the Rio Tinto Aboriginal Fund. The project leader at Griffith University for this project is the Chair for Rural, Remote, and Indigenous Oral Health. This position is sponsored by Colgate Oral Care, Australia.

\section{REFERENCES}

1. Smith M, Ash P, Gilmour AS, Austin T, Robinson PG. Outreach training: the special interest group's report. Eur J Dent Educ 2011;15(2):85-9.

2. Formicola AJ, Bailit HL. Community-based dental education: history, current status, and future. J Dent Educ 2012;76(1):98-106

3. Smith M, Lennon MA, Robinson PG. The Sheffield outreach teaching program. Br Dent J 2010;209(10):513-20.

4. Eriksen HM, Bergdahl M, Byrkjeflot LI, Crossner CG, Widstrom E, Tillberg A. Evaluation of a dental outreach teaching program. Eur J Dent Educ 2011;15(1):3-7.

5. Bazen JJ, Kruger E, Dyson K, Tennant M. An innovation in Australian dental education: rural, remote, and Indig- enous pregraduation placements. Rural Remote Health 2007;7(3):703.

6. Abuzar MA, Burrow MF, Morgan M. Development of a rural outplacement program for dental undergraduates: students' perceptions. Eur J Dent Educ 2009;13(4):233-9.

7. Johnson GE, Blinkhorn AS. Student opinions on a rural placement program in New South Wales, Australia. Rural Remote Health 2011;11(2):1703.

8. Kruger E, Jacobs A, Tennant M. Sustaining oral health services in remote and Indigenous communities: a review of 10 years experience in Western Australia. Int Dent $\mathbf{J}$ 2010;60(2):129-34.

9. Smith M, Lennon MA, Brook AH, Ritucci L, Robinson PG. Student perspectives on their recent dental outreach placement experiences. Eur J Dent Educ 2006;10(2):80-6.

10. Smith M, Lennon MA, Robinson PG. Students' clinical experience on outreach placements. Eur J Dent Educ 2010;14(1):7-11.

11. Lynch CD, Ash PJ, Chadwick BL. Student perspectives and opinions on their experience at an undergraduate outreach dental teaching centre at Cardiff: a 5-year study. Eur J Dent Educ 2010;14(1):12-6.

12. Strauss RP, Stein MB, Edwards J, Nies KC. The impact of community-based dental education on students. J Dent Educ 2010;74(10 Suppl):S42-55.

13. Bailit HL, Formicola AJ. Preface: about the dental pipeline program. J Dent Educ 2010;74(10 Suppl):S5-6.

14. Mascarenhas AK, Henshaw M. Infrastructure for a community-based dental education program: students and clinics. J Dent Educ 2010;74(10 Suppl):S17-24.

15. Lynch CD, Ash PJ, Chadwick BL, Hannigan A. Evaluation of a U.K. community-based clinical teaching/outreach program by former dental students two and five years after graduation. J Dent Educ 2010;74(10):1146-52.

16. Marshall RI, Spencer AJ. Accessing oral health care in Australia. Med J Aust 2006;185(2):59-60.

17. Skinner JC, Massey WL, Burton MA. Rural oral health workforce issues in NSW and the Charles Sturt University dentistry program. N S W Public Health Bull 2009; 20(3-4):56-8.

18. Australian Institute of Health and Welfare, Dental Statistics and Research Unit. Oral health and access to dental care: rural and remote dwellers. Adelaide: Australian Institute of Health and Welfare, Dental Statistics and Research Unit, 2005.

19. Australian Research Centre for Population Oral Health. Oral health and access to dental care in Australia: comparisons by level of education. Aust Dent J 2006;51(4):342-5.

20. Australian Institute of Health and Welfare. Aboriginal and Torres Strait Islander health performance framework 2010: detailed analyses. Canberra: Australian Institute of Health and Welfare, 2011.

21. Roberts-Thomson K, Do L. Oral health status. In: Slade G, Spencer AJ, Roberts-Thomson KF, eds. Australia's dental generations: the national survey of adult oral health 200406. Canberra: Australian Institute of Health and Welfare, 2007:81-142.

22. Mofidi M, Strauss R, Pitner LL, Sandler ES. Dental students' reflections on their community-based experiences: the use of critical incidents. J Dent Educ 2003;67(5): 515-23. 
23. Smith AE, Humphreys MS. Evaluation of unsupervised semantic mapping of natural language with Leximancer concept mapping. Behav Res Methods 2006;38(2):262-79.

24. Smith AE. Automatic extraction of semantic networks from text using Leximancer. Presentation at HLT-NAACL 2003 Human Language Technology Conference, North American Chapter of the Association for Computational Linguistics, Edmonton, Canada, 2003.

25. Sheiham A. Impact of dental treatment on the incidence of dental caries in children and adults. Community Dent Oral Epidemiol 1997;25(1):104-12.

26. Chrisopoulos S, Teusner DN. Dentist labor force projections 2005 to 2020: the impact of new regional dental schools. Aust Dent J 2008;53(3):292-6.
27. Kruger E, Tennant M. Oral health workforce in rural and remote western Australia: practice perceptions. Aust J Rural Health 2005;13(5):321-6.

28. Sheiham A, Watt RG. The common risk factor approach: a rational basis for promoting oral health. Community Dent Oral Epidemiol 2000;28(6):399-406.

29. Pitts N, Amaechi B, Niederman R, Acevedo AM, Vianna R, Ganss $C$, et al. Global oral health inequalities: dental caries task group - research agenda. Adv Dent Res 2011;23(2):211-20.

30. Marmot M. Social determinants and the health of Indigenous Australians. Med J Aust 2011;194(10):512-3.

31. Marmot M, Bell R. Social determinants and dental health. Adv Dent Res 2011;23(2):201-6. 